\title{
Erratum to: Effects of Neighborhood Walkability on Physical Activity and Sedentary Behavior Long-Term Post-Bariatric Surgery
}

\author{
Ryan E. R. Reid ${ }^{1}$ - Tamara E. Carver ${ }^{1} \cdot$ Tyler G. R. Reid $^{2}$ - Marie-Aude Picard-Turcot ${ }^{1}$ • \\ Kathleen M. Andersen ${ }^{1} \cdot$ Nicolas V. Christou ${ }^{3} \cdot$ Ross E. Andersen ${ }^{1}$
}

Published online: 19 December 2016

(C) Springer Science+Business Media New York 2016

Erratum to: OBES SURG

DOI: $10.1007 / \mathrm{s} 11695-016-2494-4$

In the original article the name of author Nicolas V. Cristou and his email address were incorrect. They are correct here.

The online version of the original article can be found at http://dx.doi. org/10.1007/s11695-016-2494-4.

Ryan E. R. Reid

ryan.reid@mail.mcgill.ca

Tamara E. Carver

tamara.carver@mcgill.ca

Tyler G. R. Reid

tyler.reid@stanford.edu

Marie-Aude Picard-Turcot

marie-aude.picard-turcot@mail.mcgill.ca

Kathleen M. Andersen

kathleen.andersen@mail.mcgill.ca
Nicolas V. Christou

nicolas.christou@mcgill.ca

Ross E. Andersen

ross.andersen@mcgill.ca

1 Department of Kinesiology and Physical Education, McGill University, 475 avenue des Pins Ouest, Montreal, QC H2W 1S4, Canada

2 Department of Aeronautics and Astronautics, Stanford University, Stanford, CA, USA

3 Bariatric Surgery, McGill University Health Center, Montreal, QC, Canada 